\title{
After All, Who Lectures the Lecturer? Exploring the Barriers Impacting the Development of a Reflective Practitioner
}

\author{
Anietie G. Ukpabio \\ 1.Doctoral Researcher of PhD in E-Research and Technology Enhanced Learning Lancaster University. \\ Lancaster, UK \\ 2.Business Analyst at IBM Client Innovation Centre. Leicester, UK
}

\begin{abstract}
Reflective practice has successfully shifted towards evolving into one of the standards of lecturers' professional development, although it would appear that it has been psychologically constricted to student lecturers alone. Because it is often the case where lecturers are submerged in a social field where it is highly necessary for them to blend continuously with the dynamics of the ever-changing field, as well as follow its rules, reflection is one of the 'performance mirror' available to lecturers. Some of the key questions that emerged in the study were - are the teaching abilities of the lecturers constrained by the social elements of reflection theories? Why is reflection not practiced by Further Education lecturers in the way it is supposed to? This research paper evaluates the notion and limitation of reflective practice in the Further Education of lecturers. With cognizance of the historical underpinning theories, criticisms and recommendations from relevant literature, this paper draws a conclusion towards reintroducing reflection in the context of Further education using educational technologies.
\end{abstract}

Keywords: Reflective practice, professional development, performance mirror, reflection, Further Education, educational technologies

DOI: $10.7176 / \mathrm{JEP} / 10-12-01$

Publication date: April $30^{\text {th }} 2019$

\section{Introduction}

Historically, there exist numerous definitions about reflective practice in education, the broadest amongst them is the definition offered by Richards (1994) who characterises reflection as a procedure of learning from our past practices, in which self-inquiry is viewed as an essential factor of a practitioner's advancement. Along that line of thought, I became familiar with another definition that I regard as a point of interest which states that, in intelligent practice, professionals participate in a nonstop cycle of self-perception and assessment so that they could grasp their behaviour and responses (Brookfield, 1995; Thiel, 1999).

Arguably, reflective practice has tended to sound credible in the field of education mostly because practitioners are consciously or subconsciously in favour of the ideation that thinking about their practice or actions of yesterday usually brings about a better today or tomorrow in practice. Although it is a contention that before reflection can be used to measure practice, there is a need to recognise the elements of reflection using an approach that allows the generalisation and limitations of reflections in certain contexts? Additionally, there is a need to compel education practitioners to peer-reflect on their practices, as well as from other possible reflective stance. Therefore, as the relationship existing between context, knowledge, and expected results of knowledge acquisition through reflection are part of reflection, informing new and experienced lecturers about reflection in further education could be more than just stating and changing how reflection is practiced.

\subsection{The problem statement}

There are numerous strategies for utilizing reflection as a part of a request to enhance a lecturer's practice, for example, composing diaries, peer reviews, lesson reports, showing portfolios, showing diaries and exercises (Moon, 2008). Other different methods for reflecting can be through utilising non-verbal systems, for example, sketching/diagrammatic exercises, role playing and dramatization (Korthagan, 1993).

Regardless of the abundance of reflection strategies, it would arguably appear that there is a cry for accomplishment in uniformity of reflective practice. Although my previous attempt to informally understand the problem in my context was quickly quenched by a self-constructed assumption that it is hard to distinguish what uniformity in reflection means and that the definition of reflection has long been besieged with the problem of appearing subjective to various practices and practitioners other than the field of education.

Specifically, in my context, when I taught a few colleges, the lesson plan comes with a lesson reflection document. The structure of this document is almost similar to the structure of "What Went Well" (WWW) and "Even Better If" (EBI) learner's assessment feedback document. The use of this document is mandatory for the PGCE students, and it was informally observed as being rarely used by qualified and experienced lecturers.

To be more factual, I have witnessed qualified and experienced lecturers use this document only during a formal lesson or OFSTED inspection. While this informal observations left me wondering if reflection is only an early-career-period practice and not for the experienced and qualified lecturers, it is important to re-acknowledge 
the existence of other reflection strategies other than paper-based.

This study explores towards if it is possible to rethink and reintroduce reflective practice in further education. As it would appear that in my context, reflection is not practiced in the right manner, and it is arguably not properly informing learning and teaching yet takes much time when done only when being observed. Although, it is uncertain if this particular problem of reflection is in any way linked to the practice or attitude of practitioners or their pedagogy of reflection.

\subsection{Study questions}

As a result of the problem statement above (see section 1.1), this research was intended to analyse the present issues related to reflective practice across experienced and trainee educators so as to comprehend better how reflective practice could be efficiently incorporated with regards to Further Education College. The particular aims of the study were conceptually embedded into the main and sub-questions of the study which were to:

Beginning with a broad question which asks: How can theories of reflective practice be reintroduced in Further Education to support the development of professional practice? It became imperative to harness the benefits of this broad question by asking some key important sub-questions which did help develop themes and strengthen the narrative thread of the literature review section. The sub-questions are as follows.

Which kind of reflective practice processes is useful for the reintroduction of reflective practice in further education?

Which features of lecturers' reflective stance are useful in the reintroduction of reflective practice in further education?

In accordance with the suggestions of some researchers (e.g., Cresswell, 2009; Patton, 2002), which demonstrates that research methods ought to be influenced by the aims of research, a qualitative method was utilised in this study. Particularly, a procedure of linking the research questions to the problem in my context and a further link with the past and emerging themes in existing literature. A more detailed account of the factors, process, and conditions that informed this method is stated in the research design section of this report.

\section{Review of relevant literature}

Historically, similar to the majority of enduring notions in education, one can trace how a lecturer is viewed as a dynamic and continuously advancing professional and reflective practitioner to the works of Dewey (1933). Reflection has rapidly emerged as one of the most prevalent concerns in lecturer education. There are literature that contains numerous instances of the success reflective practitioners are reported to have in modifying and refining their individual teaching (for example, Ghaye, 2010; Reynolds, 2011; Farrell, 2011; Camburn, 2010; Branch, 2010), and of the adoption of reflective "practices" through lecturer education programmes, (for example, Edwards and Thomas, 2010; Cropley et al., 2010; Nelson, 2012; Hagevik et al., 2012; Lie et al., 2010) and of bids for additional reform that will lead to a reflective stance in teaching (for example, Bradbury et al., 2012; DragoSeverson, 2012). However, just like most education theories, there is a risk of being hauled past what is known to the implementation of practices that are only based on suppositions, speechmaking, and conviction in what "ought to be." Regardless of how widespread reflection is as a suitable standpoint for professional education practitioners, there is not much evidence from research that associates reflection with other conditions in the professional lives of lecturers (Davies, 2012). It would also appear that there is not much known to ascertain the programmatic decisions in lecturer education on the eminence of professional readiness or growth.

\subsection{Problem-Solving, Reflection and One Big Question}

The most vital issue that could probably form the foundation upon which all ensuing work is based is the traits of reflection itself. How can theories of reflective practice be reintroduced in Further Education (FE) to support the development of professional practice? To analyse this primary issue, a start was made with the evaluation of the current literature on reflective thinking and teaching, problems associated with reflection, disapprovals of reflection, conceptual mix-ups about reflective theory and correlation between reflection and lecturers' attributes. A working definition that gives a description of the appearance of reflective practice in teaching started developing from this literature review. One of the aims of this study is to examine reflective practice within some arrays of instances and to re-conceptualise a context suitable for adoption in FE as a first step towards the debatable differentiation between reflective lecturers and their less reflective counterparts. It is vital that the presentation of these attributes has a prelude that explicitly recognises the core assumptions guiding this work.

This report is based on two assumptions directing the reintroduction of reflection theory in further education teaching and learning. Possibly the most fundamental of the underlying assumptions is that which casts reflection as a process. Instead of identifying reflection in teaching by particular characteristics of personality, values or intellectual qualities that could offer a description, it is imperative to look for ways of scrutinising the thought processes of educators alongside the actions that emerge from those ideas.

Consequentially, a further assumption is made that the process of reflection most consistent with reflective 
practitioners is the process of problem-solving. Although English language becomes a constraint towards articulating this hypothesis properly, the phrase "problem- solving" is not sufficient to the intention of this study. To start with, "problem" although not always appropriately, typically has a derogatory inference (Kim and Hannafin, 2011). Education practitioners who look-out for solutions to existing problems often have the profound sense that the state of things is not at its best and that there are deficits in need of remedies. To admit that problems are non-existent is deemed as concurrent with admitting weakness. Secondly, 'solving' frequently implies deducing one correct solution, a target which may be unsuitable or even impossible in some scenarios. Although it is inherently difficult to express an education practitioner's stance for evaluating and improving professional activities by using a better phrase than "problem solving," I do not hold the negative and restricting inferences of this phrase. It is therefore considered crucial to clarify that, in this section, with Edwards and Thomas (2010), problem is seen as, solving them through a customary and well imaginative procedure where competent practitioners try to deduce baffling or challenging phenomena, pinpoint areas of practice that bring about inquiry, define specific targets for improvement, and take up actions intended to achieve them particularly.

Correspondingly, the above notion also acknowledges that there is more to reflection than just resolving problems. Apart from identifying and defining problems and formulating and applying solutions, reflective lecturers also use this procedure to alter and augment their comprehension of specialised practice. Their comprehension is consequently reconstructed; thus, the journey of problem-solving on its own does not makeup reflection as well as learning does not, but instead consider both as crucial constituents of reflection. Furthermore, this assumption additionally dictates reflection as a continuous process. A problematic status quo to a reflective practitioner is seen as just one of many occurrences on the past, present, future continuum (Roll et al., 2011). A lecturer gauges the situation the moment there is an irregularity, depending on information from current conditions as well as past experiences, so as to settle on an action that will have an effect on future events. The past, present, and future of students, the setting and the lecturer come together in an ongoing conversation of practice as termed by Farrell (2012). Reflective practice is recursive as a process. It is continuous and functions at multiple levels in any particular time frame.

\subsection{A Stance within Reflective Practice}

In teaching, reflective practice is demonstrated as a stance towards inquiry. Here a stance is considered to be an attitude adopted when grasping during-lesson understandings. It is a large or prevalent configuration that personifies how a lecturer continuously responds to the particular conditions of their lecturing (Alexander et al., 2010). Supposing a stance concerning reflection comprises of the detection of the suitability of engagement for a precise situation in the reflective process. It is not possible for such a stance to be distinguished from distinct evident lecturer mannerisms; one can only identify a lecturer's reflective stance when taking patterns over time into consideration. While it is possible to identify meditative rational by a process, it is also feasible to use a stance to determine a meditative practitioner (Kolb and Kolb, 2012).

Evidencing reflective practice is deemed to be present in a scale individuals wavering in the prospect, capability, or inclination to reflect. It would appear irrational to anticipate constant reflection from lecturers at each and every moment. Similarly, it is likely that there are hardly any lecturers who do not engage in reflection at all. Moreover, contingent on both the context and how inclined a lecturer is to reflection, the degree of thoroughness in reflection may be different with each lecturer. Instead of categorising a lecturer as reflective or not, a presumption is made that any definition of reflection in teaching should include discernment of a spectrum thereof (Reason and Kimball, 2012).

Evidentially, reflective practice occurs within a social context education as a social activity; in general, it involves several participants (various stakeholders in the college) and occurs in a shared environment (different places in the college), the invocation of a term initially coined by Yinger (2014) as "the learning place" is adopted as a reminder of the rudimentary relationship that forms between the participants and the shared environment as they get acquainted. It is, therefore, essential to take note of the circumstantial factors when putting into consideration the reflective practice of lecturers (Boud et al., 2013). The presence of "context" implies an extra dimension even though it is almost frequently defined as "something that surrounds and influences, as environment or circumstances." Hence, context denotes the assembly, or "submergence" of the lecturer, learners, and the surrounding into a learning and teaching situation. Obviously, not all researchers agree with this assumption to a similar degree. While others regard the social context only as a secondary issue, some tend to lay major emphasis on it and employ it as the only interpretative lens for viewing reflection. The opinion for this study does not fall in any of these extremes. Even though the social context is not the exact center of an investigation for this study, it can be debatably acknowledged that reflective practice occurs in a social setting at all times (Coulson and Harvey, 2013).

\subsection{Is It Easy to Spot Lecturers that Reflect and those Who Do Not?}

Debatably, following the arguable assumption that it is possible to identify accurately the lecturers that engage in 
reflection more constantly, it would, in that case, be imperative to gain absolute familiarity with such lecturers, by examining their psychological, social, and professional traits. This medium can provide valuable information and ability to study the relationship between reflection and other lecturers' attributes. Jordi (2010), for instance, has re-suggested a link between reflectivity and both internal and external learning orientation and Opfer et al. (2011) has carried out a more recent analysis of the relationship that exists between reflection and proactive and reactive orientations to teaching. One question, under additional examination apprised by the above operational definition of reflexivity, would be if these proposals have support. One could also probe if other characteristics can be associated with reflectivity (Takahashi and Saito, 2011).

Similarly, Zeichner and Liston (1987) have pointed out that the systems through which lecturers place value are consistent with reflectivity, as mirrored for instance in their principles on student learning journey as well as their career development aspirations. Is it possible to consistently identify this relationship, using the attributes depicted above, in lecturers with varying degrees of reflectivity? Do other values, standpoints, or opinions which could in a similar manner be linked to high or low reflectivity exist? Lastly, it would be interesting to study the manifestation of lecturers' reflectivity in how they carry out the work. Roediger and Pyc (2012) has considered reflection by cognitive psychology.

\subsection{Theoretical Confusion or Practical Inability}

An issue that evidently emerged in the examined literature involves the conceptual ambiguity accompanying the phrase 'reflective practice', and the idea of reflection itself. Like most education theories, almost recently, Mann and Walsh (2013) noted that the concept of reflection is not a simple one and could denote a multifaceted collection of different approaches and attitudes that are both cognitive and philosophical. According to Edwards and Thomas (2010), presently reflection is a well-known notion leading to the irony that employment of reflection is frequently done in a way that is, in fact, unreflective. Furthermore, Reynolds (2011) stated that reflection is encouraged everywhere, devoid of the benefit of critical analysis.

The conceptual ambiguity associated with reflective practice are often written about in the form of scholarly criticisms. For example, according to Hébert (2015), reflective practice faces the risk of turning into a catchy phrase for a process that is not well defined. Visser (2010) suggests that the term "reflective practitioner" is every so often used as an ambiguous slogan instead of a concept complemented with a determined and worked out the meaning. MacKinnon et al. (2013) state that reflective practice 'is difficult to conceptualise and many aspects of it are open to debate'. Newman (1999) speaks of the classic writings of Schön on reflective practice as 'influential but most unclear.' In line with Kinsella's (2003) sentiments, reflective practice may comprise of different approaches illuminating conceptual and practical misunderstandings that have not been addressed or debated on. Jay and Johnson (2002) states that 'the use made of the concept, and therefore its perceived meaning, is in no sense a unitary and straightforward one.' Stiler and Philleo (2003) proposes that Schön uses a collection of overlapping attributes that he assembles in alignment with certain circumstances and hence does not have a clear view. Therefore, some researchers have brought forth the challenging issue of the conceptual misunderstandings that revolve around reflective practice.

Various practitioners, researchers, and educators have specific ways of structuring reflective practice and its applications. They overlook other dimensions of the theory and only put emphasis on one dimension. As stated by Ghaye (2010), there is not an agreement but several unique considerations of the definition of reflective practice. The great confusion amongst practitioners and educators has been broadly mentioned in the literature (see Kinsella, 2003; Hébert, 2015; Newman, 1999). The confusion in the application of reflective practice is so widespread and distinctive that several have suggested that the term is vulnerable to becoming an empty and inconsequential phrase that simultaneously implies everything and nothing. Newman (1999) adds weight to this vulnerability by elaborating 'Schön's work is often used uncritically to support a broad range of apparently contradictory positions.' Ferry and Ross-Gordon (1998) highlights this concern within the teaching profession.

\section{Methodology and Method}

Fundamentally, this research was underpinned by a theoretical literature review as a methodology. Very often, scholars involved in qualitative literature review researches are often reliant on a literature selection technique that produces a situation that encompasses all possible scenarios envisioned in their research plan (Poulis et al., 2013). For this study, the motive shifted from a "one size fits all" literature selection to literature that are greatly edifying to the phenomena under study. More specifically, the emphasis was on selecting literature that were associated with the conceptualisation and comprehension of reflective practice in trainee and experienced lecturers' career as well as literature that highlighted what a successful reflective practice would look like and its benefits. Furthermore, because the secondary data gathering methods used is a literature review, which further led to the invocation of the term 'narrative review (Xu and Connelly, 2010). The major determinants of the data collection instruments were the structure of my research questions, the rarity of the underlying assumptions and presence of the arguments within the selected literature. A more accurate account of the activities that took place during the secondary data 
collection is stated in the next section below (see section 3.1).

\subsection{Selecting and using the literature}

An initial grasp of the context of the topic and the common terminologies usually used in discussing the topic was performed. This yielded insight towards identifying key terms. Although, the initial list of terms generated appeared to be far from exhaustive, linking the terms to the titles in the research questions reduced the list and generated key elements. The formulation of related terms and synonyms were deployed only to broaden my search horizons wherever and whenever it seemed limited. What followed the generation of the main elements was the identification of resources to search. Unfortunately, regardless of the phenomena under study, there is no 'one size fits all' single source of information that will contain all the key elements. The starting point was the Lancaster University online library (also known as OneSearch). At some point, I further gained access to other libraries including access to some full-text academic journal articles on Google Scholar via the Lancaster University virtual private network (VPN).

Holistically, my search targeted words that matched my inclusion criteria (see inclusion criteria) while I had little emphasis on the exclusion criteria only to remind myself about what I should not be searching for. Narrowly, my search techniques began to involve the use of wildcards (wild characters), escape characters and operators like an asterisk $\left(^{*}\right)$, 'or,' 'not,' 'and.' More importantly, the currency of the articles were filtered to range between five to ten years old. Although, because the research theoretical lens is very historical, it was hard to ignore past articles that defied the literature recentness criteria. Finally, the selected articles were collated, evaluated and linked in order to enhance the chain of evidence.

\subsection{Exclusion Criteria}

- $\quad$ Recent studies that were over ten years old

- $\quad$ Studies on other field of studies professional development via effective reflection;

- $\quad$ Studies that featured the success of reflective practices in other fields of study;

- $\quad$ Studies that featured the failure of reflective practice in other fields of study;

- $\quad$ Studies that argued how practitioners other than lecturers see reflection;

- $\quad$ Studies that were critical about several processes of reflective practice in other fields of study;

- $\quad$ Studies that discussed the theoretical confusion of reflective practice in other fields of study;

- Studies that discussed the practical inability of reflective practice in other fields of study;

- $\quad$ Studies that discussed or attempted to discuss the differences between practitioners other than lecturers that reflect and those who do not reflect;

To sum it up, the contents of the literature were examined in order to extricate evolving issues identified as closely associated to the research questions from the selected articles. Along that line of thought, a conceptualisation of the reintroduction of reflective practice in my context became feasible.

\subsection{Inclusion Criteria}

- $\quad$ Recent studies that ranged between five to ten years old;

- $\quad$ Studies on lecturer professional development via effective reflection;

- $\quad$ Studies that featured the success of reflective practices in education;

- $\quad$ Studies that featured the failure of reflective practice in education;

- Studies that argued how lecturers see reflection;

- $\quad$ Studies that were critical about several processes of reflective practice in education;

- $\quad$ Studies that discussed the theoretical confusion of reflective practice in education;

- $\quad$ Studies that discussed the practical inability of reflective practice in education;

- $\quad$ Studies that discussed or attempted to discuss the differences between lecturers that reflect and those who do not reflect;

\subsection{Limitations of Using Literature Review as a Methodology}

Amongst the benefits of utilising a literature review methodology, there are drawbacks - and a highlight is stated below about the two principal drawbacks. The primary drawback falls within the category of criticism that emerges from the wrong selection of literature. The selected literature may not be an ideal fit; understandings cannot be oversimplified, justifications can be subjective, and the researchers' prejudice even at the stage of deciding inclusion and exclusion criteria can affect the study. Along that line of thought, a major difficulty of this study was to thoroughly build up a comprehension of the problem and the associated contexts while remaining isolated from the situation (Yin, 2013).

Also, because the literature selection and analysis techniques of phenomenography and ethnography overlap, procedures, for example, identifying search terms, wordings, linking terms, variant spellings, finding phrases and result collating is difficult, and it has been vital for researchers to submerge themselves in the circumstances that 
they are researching by reconstructing meaning where possible.

\section{Discussion of Findings - Reintroducing Reflection}

Methodologically, a major focus in this section drew inspiration from Moon (2005), particularly the "Guide for Busy Academics - Learning through Reflection" publication. It appeared to efficiently convey the main points, and a major appreciation about this publication was for its briefness. Moon starts off with the conventional notion of reflection, proposing that reflection can be thought of as either a status or as a resolute undertaking.

According to Moon (2005), reflection can be supportive to learning through four ways. The first one being speed (decelerating learning). The second is sense-making (forming material); the third as ownership (annexation) and the fourth is metacognition (putting into consideration one's learning). Although she defines reflection as a kind of cognitive process employed to satisfy a purpose or to accomplish an intended result. She adds that reflection is utilised to grasp rather complex or ambiguous notions better, and it is mostly established by processing possibly already present emotions, knowledge, and comprehension again and again.

Inevitably, there are doubts concerning the emphasis Moon has put on the emotionality of reflection. Nonetheless, an effort can be made to understand her point of view, considering that one of the acknowledged objectives of reflection in learning is to make the learner feel like they own the material. It, however, appears that the emotional facets are to some degree exaggerated in this piece. One of the reasons for reflecting is to endeavour in going beyond one's instantaneous responses or individuality and attempt to gain a comprehensive understanding of a theory or problem. It is apparent that Moon (2005) is aware of this when she makes an allusion to the notion that reflection is a means through which one can have power over their emotions when learning.

Practically, I am more drawn to the sense-making conception of reflection. It is contextually presented regarding deep and surface learning. I am however of the opinion that practically, we are still under the jurisdiction of individual reflection and most times, an inter-subjective aspect to reflection is present. This medium is evident in my subject area, which takes the form of dialogue. Furthermore, lecturers of psychology and business are actively urged to use the first person when writing during their subject specialist training. Moon sees this as a possible obstacle in reflection.

On e-reflection, educationally, as a busy education professional, the principal positioning of reflective learning in the electronic portfolio/PDP approach is another point highlighted in Moon (2005) piece. The electronic portfolio approach can somehow be grasped as a means of elucidating, as part of learning, the type of reflection that mostly occurs in a less apparent manner. Even as a technology enthusiast, I am uncertain that this essentially reinforces better (or increased) learning from the perspective of the lecturer: taken together, it is not necessary for one to consciously interpret their actions as reflection so as to reflect genuinely. Furthermore, I have highlighted my conclusive stance about e-reflection in the concluding paragraph of this chapter.

Also, in an attempt to expound on the delineation of beneficial strategies that can be implemented to develop reflection in lecturer education programmes and careers, some critics offer some helpful acumens. In line with Feiman-Nemser (2012), lecturers are just like learners in that they have to structure their knowledge of the ambiguous teaching business. She puts emphasis on the role of the "voice" in this continuous process, alongside the necessity of dialogue amongst lecturers and students and with others in the pursuit to probe, investigate, defy and give descriptions and explanations (Shulman and Sherin, 2004). When advocating for reflection, there are two identifiable dimensions. Firstly, verbalizing the truth as perceived, with the intention of expressing and making ideas and convictions clear. This medium is in itself significant and gives a valuable foundation for reflection. Secondly, voicing one's opinions and being heard. She once more points out the importance of learning in paying attention to the context of what one is, in fact, stating and understanding it. She, however, highlights how important it is for others actually to listen, a trait that is rare amongst both lecturers and lecturer educators, and beneficial to cultivate in pre-service lecturers. Such a stance backs the notion that there are even grander prospects for oral reflection within the further education sector. It ought to facilitate the auxiliary development of reflective capabilities, preceding particularly to the personal discourse forms which could offer great acumens.

Evidentially, reflective practice that is operational encompasses cautiously making an allowance for both "seeing" and "action" to augment the potential of experiential learning. It is sometimes a challenge in the practice setting to separate these two elements - and is somehow a subjective distinction in its own right - because of their impact on the subject of apprehension from how lecturers drift through experiences, heed to the never-ending demands to make decisions, and how lecturers consciously and subconsciously sieve how lecturers act and respond. One can either deem these requirements as impeding and overloading factors or as prospects for learning that could be understood from diverse points of view (Ghaye, 2010).

A lecturing style that is regularly used after practicum is for lecturer educators to "excerpt" the learning from the experiences of trainee lecturers (or lecturers to be) so that they can, in presentation, revert these experiences to them in techniques that give valuable insights that were previously unrecognisable. Still, if the trainee lecturer as a learner is truly the centre of attention, then what is of most importance is how well they analyse and internalise experience - rather than the sieving, development, and sharing of knowledge by the lecturer educator (Reynolds, 
2011).

Recently, I have come to terms in comprehending this elusive distinction. It is quite a challenge to comprehend it and saying it here is not an assurance that it is now meaningful to the readers as well. The challenge lies in the fact that as much as the knowledge gained might be similar, the method in evolving the knowledge is very unlikely. It is of significant bearing which the learner is, in high association with the effective reflective practice's location of occurrence. In my context, this is mostly the lecture room, staff room, and the lecturer's home. Therefore, to deliberate once more on the conventional teaching surrounding debriefing. It is not rare for trainee lecturers to be asked to get in small groups and share their developing and developed professional experiences. In my limited experience, they usually find this to be engaging and stimulating (Farrell, 2012).

Reasonably, one may ask what the outcomes of such tasks are, other than some form of consolation in acknowledging that others share in your challenges and predicaments, or in knowing that it is not easy transiting from trainee lecturer to experienced lecturer (or from newcomer to old-timer), or that there are solutions to some commonplace issues and so on. If these small groups of trainee lecturers, on the other hand, are requested to come up with contentions about their developing or developed professional practice following this sharing, the conclusions can vary qualitatively from that of the acknowledgment above and support outcomes. This variance is further broadened when trainee lecturers record and share these contentions with their colleagues. This act of recording and sharing can be effortlessly done using technological tools (mobile application or Web 2.0) like "Recap."

Through this, their effective reflective practice could be obvious in how their prospects for impending action are augmented owing to the different points of view they could acquire - the presumptions they might had undervalued could be confronted, and so it could be difficult to justify their "customary" and/or "evolving" practice. Although they could then substantiate their practice, they might not justify it because, through the restructuring that comes with asserting one's views, the proverbial could be foreign, thereby fostering an unprejudiced attitude. It is vital for one to be capable of identifying, developing, and verbalizing knowledge because it makes effective reflective practice purposeful and valuable. Furthermore, it is an effectual means of informing practice because the tacit carries more weight and becomes unequivocal and beneficial.

Perhaps the best demonstration of this line of reasoning is looking at the effective reflective practice mostly with the mindset of taking advantage of various technological advancements available at the disposal of further education trainee lecturers and experienced lecturers.

\section{Conclusion, Recommendations And Limitations}

This paper has mildly answered some key fundamental questions, most importantly addressing the essential elements that are paramount to reintroducing reflective practice in further education and the suitable research agenda that could increase the comprehension of reflectivity by FE lecturers. The answers to the research question have been overly structured about how reflectivity is viewed as the inclination of a lecturer towards involving themselves in a careful process where they identify glitches in their practice and seek resolutions that could lead to valued outcomes on student learning journey. Just like the predisposition to classify lecturers as reflective or not has been eluded, so has the predisposition to suppose that those who are highly reflective make better lecturers than those who are less reflective. It is presumed that the research agenda that such a running definition backs would be beneficial, both in enhancing our comprehension of professional conduct in lecturing and in directing the groundwork for entrants into the expert and general area of practice of lecturing (Hagevik et al., 2012).

It especially underscores the manner in which experiential knowledge development (transiting from trainee lecturer to skilled lecturer), following effective reflective practice, can result in acknowledgement and delivery of professional knowledge that shows how theory and practice entwine in modes that finally defy the conventional interpretation of these as characterised by contradiction (Orr and Simmons, 2010), an interpretation that has led to the concept of a theory-practice disparity evidenced in the literature review section of this report. Challenging this disparity between theory and practice is important. An imagination of appropriate reflective practice is one approach through which lecturer preparation programmes can incorporate the two in ways that are positively consequential. Several of the latest studies (e.g. Orr and Simmons, 2010; Copland, 2010) take note of the continuous struggles that lecturer education programmes in numerous countries face when deciding whether to begin with theory or with practice, and that, in the conventional styles lecturer preparation, the idea of interweaving the two is to a huge extent disregarded. Orr and Simmons (2010) provided a brief conceptual comparison of the conventional lecturer education programme with the realistic lecturer education programme (the programme as it should be). An important concern that was brought up was placing the student teacher as a learner in a curriculum designed resultant of actual experiences and restructured through collaboration amongst learners. Nonetheless, this cannot be viewed as, a "wheel reinvention" but as a technique of adding meaning to learning for trainee lecturers.

Since the challenge several lecturer preparation programmes face is making sure that trainee lecturers' real situations go beyond their professional practice. If creating experiential learning is to result truly in a comprehension and advancement of professional knowledge, then employing actual circumstances is vital when 
looking at effective reflective practice. Additionally, professional knowledge undoubtedly has to be meaningful to be useful to lecturers. Lecturer preparation thus provides a means by which lecturer can get sensitised to the knowing process and, thereby, galvanize them professionally.

Reflection repeatedly comes up in conceptualising the practice setting, and it is one chief practice that has for a long time been acknowledged as a significant and beneficial thought process (Schön, 1983; Pedler, Burgoyne, and Boydell, 1991, 1996; Dewey, 1933; Kolb and Fry, 1975). Even though some lecturer education programmes have integrated the notion of reflection into their course constructions, how it is adopted and how effectively it is implemented could still be constrained by the chiefly conventional disposition of the programmes. Reflection, therefore might more often than not be a created subject matter instead of being a subject matter for the trainee lecturers to create.

Owing to reflection being exceedingly functional and judicious in enhancing the comprehension one has of the practice setting, it faces being tossed around, misconstrued, and remains open to different interpretations as it is employed differently by various people and settings to draw attention to specific facets of practice (Jay and Johnson, 2002). It was partial because of this multiplicity of opinions and interpretations that compelled me to explore towards rethinking and reintroducing reflective practice in my context.

Effective reflective practice is founded on the capability to structure and restructure the practice setting, by using action to grow and react to this structuring. This boosts the practitioner's wisdom apathy and, as a precise result, there is backing for the delivery of professional knowledge. In my limited opinion, at best the context learned following reflection and reflection itself are similarly constructive. The 'reflective practitioner' is genuinely able to respond to the necessities, concerns, and apprehensions that are so vital in modelling practice due to the development of knowledge and comprehension of the practice setting and the capacity to identify and counter such knowledge (Kinsella, 2003).

The risk in reflection is that forward practice could continue being unapprised if the practice is restricted to backward comprehension. If practical learning is of significance, it follows that rational reflection is imperative, and clearly, lecturer preparation is the best environment for it to be introduced and cultivated.

\section{References}

Alexander, P., van Loggerenberg, J., Lotriet, H. and Phahlamohlaka, J. (2010). The use of the repertory grid for collaboration and reflection in a research context. Group Decision and Negotiation, 19(5), pp.479-504.

Barrett, T. and Moore, S. (2010). New approaches to problem-based learning: Revitalising your practice in higher education. Routledge.

Boud, D., Keogh, R. and Walker, D. (2013). Promoting reflection in learning A modeli. Boundaries of adult learning, 1, pp.32-57.

Bradbury, H., Frost, N., Kilminster, S. and Zukas, M. (2012). Beyond reflective practice: New approaches to professional lifelong learning. Routledge.

Branch, W.T., 2010. The road to professionalism: reflective practice and reflective learning. Patient Education and Counseling, 80(3), pp.327-332.

Britt, L. (2012). Why we use service-learning: A report outlining a typology of three approaches to this form of communication pedagogy. Communication Education, 61(1), pp.80-88.

Brookfield, S. (1995). Becoming a critically reflective teacher. San Francisco: Jossey-Bass.

Camburn, E.M. (2010). Embedded teacher learning opportunities as a site for reflective practice: An exploratory study. American Journal of Education, 116(4), pp.463-489.

Collins, H. (2010). Creative research: the theory and practice of research for the creative industries. Ava Publishing.

Copland, F. (2010). Causes of tension in post-observation feedback in pre-service teacher training: An alternative view. Teaching and Teacher Education, 26(3), pp.466-472.

Coulson, D. and Harvey, M. (2013). Scaffolding student reflection for experience-based learning: a framework. Teaching in Higher Education, 18(4), pp.401-413.

Cresswell, J. (2009). Research design: Qualitative, quantitative, and mixed methods approaches. Thosands Oaks, CA: Sage.

Cropley, B., Hanton, S., Miles, A. and Niven, A. (2010). Exploring the relationship between effective and reflective practice in applied sport psychology. Sport Psychologist, 24(4), p.521.

Davies, S. (2012). Embracing reflective practice. Education for Primary Care, 23(1), pp.9-12.

Dewey, J. (1933). How we think: A restatement of the relation of reflective thinking to the educative process. Boston: D.C. Heath and Company.

Drago-Severson, E. (2012). The Need for Principal Renewal: The Promise of Sustaining Principals through Principal-to-Principal Reflective Practice. Teachers College Record, 114(12), p.n12.

Edwards, G. and Thomas, G. (2010). Can reflective practice be taught?. Educational Studies, 36(4), pp.403-414.

Edwards, G. and Thomas, G. (2010). Can reflective practice be taught?. Educational Studies, 36(4), pp.403-414.

Edwards, G. and Thomas, G. (2010). Can reflective practice be taught?. Educational Studies, 36(4), pp.403-414. 
Farrell, T. (2012). Reflecting on reflective practice:(re) visiting Dewey and Schön. TESOL Journal, 3(1), pp.7-16.

Farrell, T. (2012). Reflecting on reflective practice:(re) visiting Dewey and Schön. TESOL Journal, 3(1), pp.7-16.

Farrell, T.S. (2011). Exploring the professional role identities of experienced ESL teachers through reflective practice. System, 39(1), pp.54-62.

Feiman-Nemser, S. (2012). Teachers as Learners. Harvard Education Press. 8 Story Street First Floor, Cambridge, MA 02138.Feiman-Nemser, S., 2012. Teachers as Learners. Harvard Education Press. 8 Story Street First Floor, Cambridge, MA 02138.

Fenwick, T., Nerland, M. and Jensen, K. (2012). Sociomaterial approaches to conceptualising professional learning and practice. Journal of Education and Work, 25(1), pp.1-13.

Ferry, N. and Ross-Gordon, J. (1998). An inquiry into Schön's epistemology of practice: Exploring links between experience and reflective practice. Adult Education Quarterly, 48(2), pp.98-112.

Finlay, L. (2008). Reflecting on 'Reflective practice'. PBLB paper, 52.

Galea, S. (2012). Reflecting reflective practice. Educational Philosophy and Theory, 44(3), pp.245-258.

Ghaye, T. (2010). Teaching and learning through reflective practice: A practical guide for positive action. Routledge.

Ghaye, T. (2010). Teaching and learning through reflective practice: A practical guide for positive action. Routledge.

Hagevik, R., Aydeniz, M. and Rowell, C. (2012). Using action research in middle level teacher education to evaluate and deepen reflective practice. Teaching and Teacher Education, 28(5), pp.675-684.

Hébert, C. (2015). Knowing and/or experiencing: a critical examination of the reflective models of John Dewey and Donald Schön. Reflective Practice, 16(3), pp.361-371.

Higgins, D. (2011). Why reflect? Recognising the link between learning and reflection. Reflective Practice, 12(5), pp.583-584.

Jay, J. and Johnson, K. (2002). Capturing complexity: A typology of reflective practice for teacher education. Teaching and teacher education, 18(1), pp.73-85.

Jay, J. and Johnson, K. (2002). Capturing complexity: A typology of reflective practice for lecturer education. Teaching and lecturer education,18(1), pp.73-85.

Jordi, R. (2010). Reframing the concept of reflection: Consciousness, experiential learning, and reflective learning practices. Adult Education Quarterly, p.0741713610380439.

Kim, M. and Hannafin, M. (2011). Scaffolding problem solving in technology-enhanced learning environments (TELEs): Bridging research and theory with practice. Computers \& Education, 56(2), pp.403-417.

Kinsella, E. (2003). Toward understanding: critiques of reflective practice and possibilities for dialogue. In 23rd Annual Conference of the Canadian Association for the Study of Adult Education. Victoria, University of Victoria.

Kolb, A. and Kolb, D. (2012). Experiential learning theory. In Encyclopedia of the Sciences of Learning (pp. 12151219). Springer US.

Kolb. D. and Fry, R. (1975) Toward an applied theory of experiential learning. in C. Cooper (ed.) Theories of Group Process, London: John Wiley

Korthagen, F. (1993). Two modes of reflection. Teaching and Teacher Education, 9(3), 317-326.

Lie, D., Shapiro, J., Cohn, F. and Najm, W. (2010). Reflective practice enriches clerkship students' cross-cultural experiences. Journal of general internal medicine, 25(2), pp.119-125.

MacKinnon, A., Clarke, A. and Erickson, G. (2013). What We Owe to Donald Schön: Three Educators in Conversation. Phronesis, 2(1), pp.89-99.

Mann, S. and Walsh, S. (2013). RP or 'RIP': A critical perspective on reflective practice. Applied Linguistics Review, 4(2), pp.291-315.

McKernan, J. and McKernan, J. (2013). Curriculum action research: A handbook of methods and resources for the reflective practitioner. Routledge.

Moon, J. (2005) 'Guide for busy academics no. 4: learning through reflection' (online), The Higher Education Academy. Available from: http://www.heacademy.ac.uk/assets/York/documents/resources/resourcedatabase/id69_guide_for_busy_aca demics_no4.doc (accessed 2 July 2016).

Moon, J. (2008). Reflection in Learning \& Professional Development Theory \& Practice. Routledge-Falmer Taylor and Francis Group. Great Britain.

Nelson, S. (2012). The lost path to emancipatory practice: towards a history of reflective practice in nursing. Nursing Philosophy, 13(3), pp.202-213.

Newman, S. (1999). Constructing and critiquing reflective practice 1. Educational Action Research, 7(1), pp.145163.

Opfer, V., Pedder, D. and Lavicza, Z. (2011). The role of teachers' orientation to learning in professional development and change: A national study of teachers in England. Teaching and Teacher Education, 27(2), 
pp.443-453.

Orr, K. and Simmons, R. (2010). Dual identities: the in-service teacher trainee experience in the English further education sector. Journal of Vocational Education \& Training, 62(1), pp.75-88.

Patton, M. (2002). Qualitative research and evaluation methods. Thousand Oaks, CA: Sage.

Pedler, M., Burgoyne, J. and Boydell, T. (1991, 1996) The Learning Company. A strategy for sustainable development, London: McGraw-Hill.

Poulis, K. Poulis, E. and Plakoyiannaki, E. (2013). The role of context in case study selection: An international business perspective. International Business Review, 22(1), pp.304-314.

Reason, R. and Kimball, E. (2012). A new theory-to-practice model for student affairs: Integrating scholarship, context, and reflection. Journal of Student Affairs Research and Practice, 49(4), pp.359-376.

Reynolds, M. (2011). Reflective practice: origins and interpretations. Action Learning: Research and Practice, 8(1), pp.5-13.

Richards, J. (1994). L'insegnamento linguistico in una prospettiva riflessiva. In L. Mariani, (ed), L'autonomia nell'apprendimento linguistico. Florence (Italy): La Nuova Italia Editrice, 117-132.

Robinson, K. and Webber, M. (2013). Models and effectiveness of service user and carer involvement in social work education: A literature review. British Journal of social work, 43(5), pp.925-944.

Roediger, H. and Pyc, M. (2012). Inexpensive techniques to improve education: Applying cognitive psychology to enhance educational practice. Journal of Applied Research in Memory and Cognition, 1(4), pp.242-248.

Roll, I., Aleven, V., McLaren, B. and Koedinger, K. (2011). Improving students' help-seeking skills using metacognitive feedback in an intelligent tutoring system. Learning and Instruction, 21(2), pp.267-280.

Schmidt, H., Rotgans, J. and Yew, E. (2011). The process of problem-based learning: what works and why. Medical education, 45(8), pp.792-806.

Schön, D. (1983). The reflective practitioner: How professionals think in action. New York: Basic Books.

Shulman, L. and Sherin, M. (2004). Fostering communities of teachers as learners: Disciplinary perspectives. Journal of curriculum studies, 36(2), pp.135-140.

Stiler, G. and Philleo, T. (2003). Blogging and blogspots: An alternative format for encouraging reflective practice among preservice teachers. Education, 123(4), p.789.

Takahashi, S. and Saito, E. (2011). Changing pedagogical styles: a case study of The Trading Game in a Japanese university. Teaching in Higher Education, 16(4), pp.401-412.

Thiel, T. (1999). Reflection on critical incidents. "Prospects, 14" (1), 44-52

Thompson, N. and Pascal, J. (2012). Developing critically reflective practice. Reflective Practice, 13(2), pp.311325.

Trehan, K. (2011). Critical action learning. Action learning in practice, pp.163-171.

Valli, L. (1992). Reflective lecturer education: Cases and critiques. Suny Press.

Visser, W. (2010). Schön: Design as a reflective practice. Collection, (2), pp.21-25.

Williams, R. and Grudnoff, L. (2011). Making sense of reflection: A comparison of beginning and experienced teachers' perceptions of reflection for practice. Reflective Practice, 12(3), pp.281-291.

$\mathrm{Xu}, \mathrm{S}$. and Connelly, M. (2010). Narrative inquiry for school-based research. Narrative Inquiry, 20(2), pp.349370.

Yin, R. (2013). Case study research: Design and methods. Sage publications.

Yinger, N. (2014). A Formative Evaluation of a Collaborative Problem Solving Instructional Method for a ClientBased Globally-Focused Undergraduate Program (Doctoral dissertation, Ohio University).

Zeichner, K. (1994). Research on lecturer thinking and different views of reflective practice in teaching and lecturer education. Lecturers' minds and actions: Research on lecturers' thinking and practice, pp.9-27.

Anietie Ukpabio, BSc (Hons), MSc, MBA, Cert Ed, MABE, MBCS, QTLS, FHEA I am a PhD Researcher at Lancaster University and a certified Business Analyst at IBM Client Innovation Centre.

My major interest posits in conducting research into the connections between our material surroundings, the technologies (beyond computers) that permeate them, and the ways we act, think and learn. Two recurring interests are how institutions design and evaluate their built environment domain to support opportunities for learning. More general interests include Activity Theory, networked and collaborative learning. Additionally, I also am concerned with collaborative work and group discussion in digitally-mediated environments, with a theoretical and practical commitment to social justice and equity within learning communities. I am interested in understanding the ways that sociocultural and sociotechnical elements inherent in applications of digital education operate to marginalise students who fall outside the ideations of dominant ideology.

Apart from my previous software and IT industry experience, I am also a qualified teacher and my previous teaching background involves being a former Computing Lecturer at East Kent College, New Vic College and City College Norwich.

My major qualifications are a first class honours degree in Computing from the University of Greenwich, an MSc. 
distinction in Information Technology from the Cardiff Metropolitan University, an MBA from University of Northampton.

Acknowledgement: This research was undertaken as part of the $\mathrm{PhD}$ in E-research and Technology Enhanced Learning in the Department of Educational Research at Lancaster University. I am pleased to acknowledge the contribution of lecturers and peers in supporting the development of this study and its report as an assignment paper. 